

\title{
Graphical User Interface for LTFATE Version 2.0
}

PURPOSE: This technical note (TN) details development of a new ARCVIEW-based graphical user interface (GUI) for the Long-Term FATE of dredged material (LTFATE) model, Version 2.0. This new GUI is a product of the Dredging Operations and Environmental Research (DOER) Near Field modeling of Sub Aqueous Dredged Material Placements work unit. This work unit was developed to upgrade all parts of the LTFATE model to reflect current state-of-the-art methods in sediment transport that can be applied at the scale of LTFATE (configurations of 200- to 10,000-m length and time periods of several hours to several years) and can be used with the expected level of data available for site conditions.

BACKGROUND: The LTFATE model was developed originally under the Dredging Research Program (DRP) as a site analysis tool for the storm and ambient condition induced dispersion of sediment from dredged material mounds in open water (Scheffner et al. 1995). The model has since been used for multiple U.S. Army Corps of Engineers projects, many pertaining to regulatory agency approval for new dredged material disposal sites.

A DOS-based GUI was developed for the Version 1 model and placed in the U.S. Army Engineer Research and Development Center Automated Dredging and Disposal Alternatives Modeling System (ADDAMS) (http://www.wes.army.mil/el/elmodels/). Under the web-accessed ADDAMS, the user downloads a program file containing a self-extracting, compressed archive of the LTFATE installation routine. The LTFATE program is then installed on the user's computer using a special install routine included in the downloaded software. The documentation for Version 1.0 is also in ADDAMS in an Adobe Acrobat Version 3 format (pdf).

Multiple applications of LTFATE in different regions, with different project goals identified model shortcomings that limited model applicability and accuracy. Therefore, under the DOER program, a work unit was developed to incorporate modifications to the model to reflect state of the art understanding of sediment transport methods and to expand the variety of locations where the model would be applicable. This work unit has already developed improved methods for estimating cohesive sediment transport, assessing the impact of bottom shear stress through a wave-current interaction algorithm (Gailani 1998), and is presently developing a more detailed sand transport algorithm.

This document describes a new GUI developed for LTFATE Version 2.0, which includes the improved cohesive transport and wave-current shear stress routines. Additional goals of this work unit include improved GUIs for updated versions of the model and a new user manual. The final DOER version of LTFATE (Version 3.0), final GUI, and final LTFATE users guide will replace the present LTFATE Version 2.0, the GUI described in this document, and the three references presently available to support application of Version 2.0. The three references are (1) the LTFATE Version 1.0 users guide (Scheffner et al. 1995) for description of the hydrodynamics, transport, and 
noncohesive sediment erosion routines; (2) DOER Technical Note DOER-N1 which describes input requirements for the improved cohesive sediment transport and wave-current shear stress submodels (Gailani 1998); and (3) a users guide for the GUI described in this document (Applied Science Associates (ASA) 1999).

LTFATE GUI: LTFATE Version 2, described in TN DOER-N1 (Gailani 1998), requires a series of user inputs not required in Version 1.0. Although this makes the model complex, it provides the user the ability to incorporate site specific data that was not previously an option in Version 1.0. The incorporation of site specific data improves the accuracy of the simulations (i.e., reduces the error bar). The user may also depend on default values, which would provide error ranges similar to Version 1.0. In addition, this version provides the user with the ability to perform more detailed sensitivity analyses that were not previously possible. Although this ability has been successfully applied to various projects already, usage required a detailed understanding of the code because no GUI was available. The present GUI is an Arcview-based system (Environmental Systems Research Institute (ESRI) 1992) that leads the user step-by-step through the input process as well as through the output display process. The system requires Arcview version 3.0 or higher. LTFATE Version 2.0 requires significantly more user input for cohesive sediment transport than Version 1.0. The new framework provides the user with the flexibility required for reliable predictive techniques in cohesive erosion, transport, and deposition. Wherever possible, parameters were incorporated into the code to simplify model input, but the model still requires an extensive set of user-defined parameters specifying sediment bed conditions (see Gailani 1998). These parameters are input to the model through the Version 2.0 GUI.

The Version 2.0 LTFATE and GUI can be downloaded from the DOER Web site (http://www.wes.army.mil/el/dots/doer/) or can be provided to the user on a CD available by contacting the point of contact listed at the end of this TN. The program SETUP.EXE is then executed by using Windows Explorer on the $\mathrm{CD}$ or the directory to which the code was downloaded. The LTFATE Version 2.0 users guide (ASA 1999) is also available on the Web site and CD. This provides step-by-step instructions for installing and using LTFATE Version 2.0. The user follows instructions provided by the setup executable to install LTFATE and the GUI.

It is assumed that the user has a basic understanding of and access to Arcview before using this tool. An LTFATE extension should be added to the user's Arcview project from the Arcview file menu. From the LTFATE menu in Arcview, the user can then create or specify input, run LTFATE or view model output (Figure 1).

Model input tools include methods for specifying an input (initial) mound bathymetry; entering locations on the grid at which time series of data will be saved; developing time series input for current and wave parameters, accessing an ADCIRC (Luettich, Westerink, and Scheffner 1992) ocean circulation database for current and stage elevation as LTFATE input; specifying or developing an initial mound bathymetry; specifying cohesive sediment bed properties. The LTFATE Version 2.0 users guide is designed to incorporate the specified inputs into files that can be used as input to the LTFATE model. The user-developed inputs can be saved as separate files prior to running the model. The files can be modified or deleted by the user at any time. 




Figure 1. LTFATE menu in Arcview

LTFATE model setup window is displayed when the user selects Run LTFATE Model from the LTFATE menu (Figure 1). This window has four tabs. The first tab permits the user to name the scenario as well as specify sediment grain size parameters and mound bathymetry (Figure 2). The origin in the mound bathymetry file referenced to an arbitrary origin set in the bathymetry file. The second tab permits the user to provide current and wave input files (Figure 3). The input prompts to this tab will vary depending on the user selection of long-or short-term (storm) simulation. The third tab is the user specified sediment bed properties (Figure 4). If a cohesive sediment bed option is chosen in tab 1, then the user must specify sediment bed properties for a layered bed (Gailani 1998). The fourth tab (Figure 2) allows the user to specify time series output locations. The Run LTFATE button (Figure 2) then initiates the simulation.

LTFATE output can be viewed using the View Model Output or Mound Cross-Section options in the LTFATE menu (Figure 1). The output provides bathymetric contours of mound bathymetry, bottom shear stress, suspended solids concentration, and change in bathymetry at user-specified contour intervals (Figure 5). The user also has the option of viewing mound contours and their change with time to analyze mound migration or dispersion.

FUTURE PLANS: Improved algorithms for sand transport are currently being developed that will replace the present total load formula with formulae for bed and suspended load. This will improve 
ERDC TN-DOER-N8

April 2001

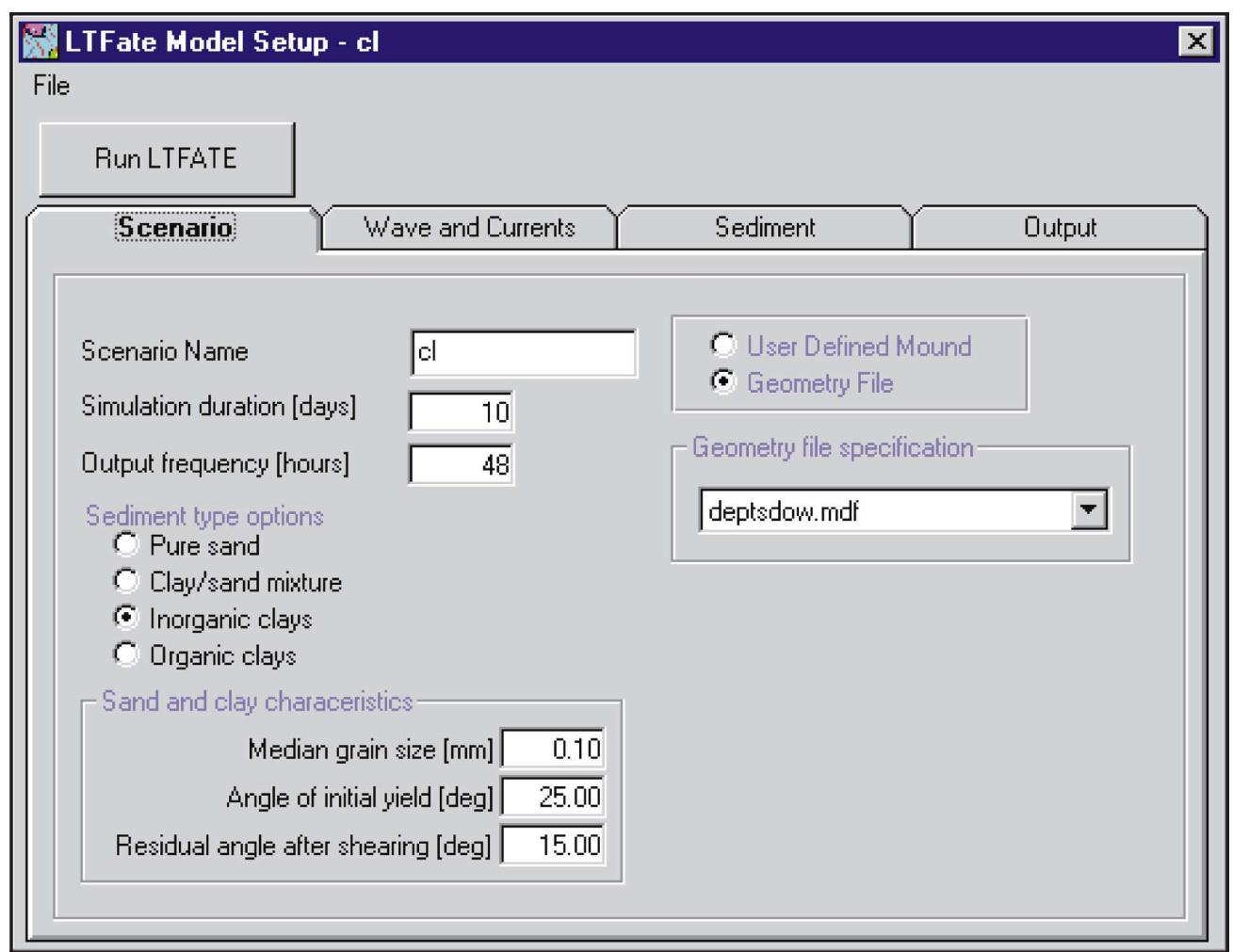

Figure 2. LTFATE model setup scenario input tab

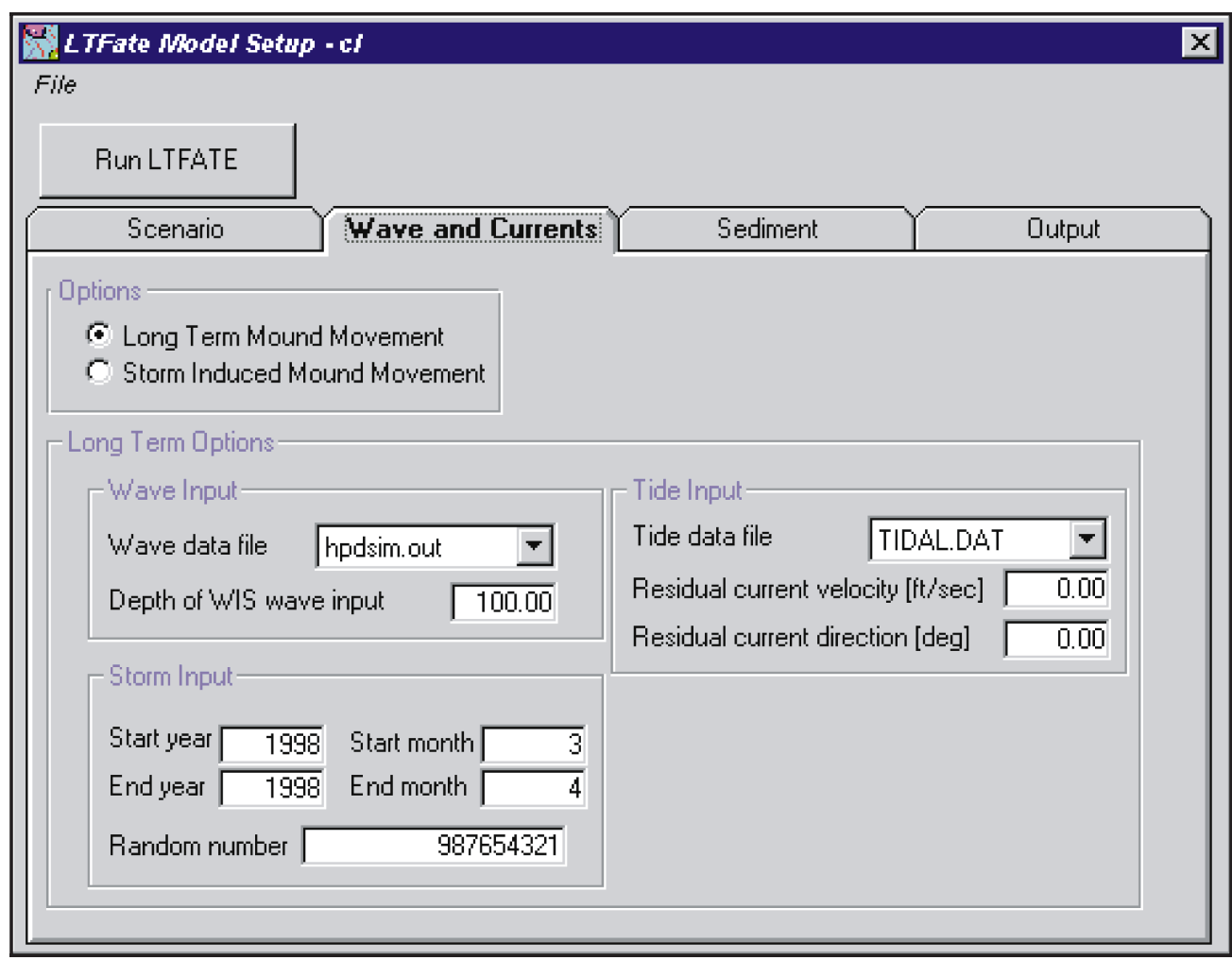

Figure 3. LTFATE model setup wave and currents input tab 




Figure 4. LTFATE model setup sediment input tab

\section{LTATE Output}

\begin{tabular}{llll}
\hline Cancel & Output Flle \\
\hline
\end{tabular}

Dutput File Types

(๘) Bathymetry [.tbty]

C Bottom Stress [.tau]

C Particle Concentration (.con)

C Bathymetry Difference [.tot]

Time Steps

\begin{tabular}{|c|c|}
\hline 00 & ㅅ \\
\hline 48 & \\
\hline 96 & \\
\hline 144 & \\
\hline 192 & \\
\hline 240 & \\
\hline & 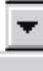 \\
\hline
\end{tabular}

Figure 5. LTFATE output window 
predictions in high shear stress regimes. In addition, algorithms are being developed that will permit both sand and cohesive sediment transport to be simulated during a single run. These improvements will be accompanied by a detailed users guide describing all methods and their application as well as a new non-Arcview based GUI.

ACKNOWLEDGMENTS: This GUI was developed by Applied Science Associates (ASA), Inc., under a contract provided by the DOER program. Mr. Eoin Howlett was the principal investigator for ASA. Research staff included Mr. Tatsu Isaji and Mr. Chris Galagan.

POINTS OF CONTACT: For technical assistance, or to obtain copies of LTFATE and the GUI, contact Dr. Joseph Gailani (601-634-4851, Joe.Z.Gailani@erdc.usace.army.mil), the focus area chairman, Mr. Jim Clausner (601-634-2009, James.E.Clausner@erdc.usace.army.mil), or the Program Manager of the Dredging Operations and Environmental Research Program, Dr. Robert M. Engler (601-634-3624, Robert.M.Engler@erdc.usace.army.mil). This TN should be cited as follows:

Gailani, J. Z., Howlett, E., Isaji, T., and Galagan, C. (2001). "Graphical user interface for LTFATE Version 2.0," DOER Technical Notes Collection (ERDC TN-DOER-N8), U.S. Army Engineer Research and Development Center, Vicksburg, MS. www.wes.army. mil/el/dots/doer

\section{REFERENCES}

Applied Science Associates, Inc. (1999). “Getting started with LTFATE,” Report prepared for U.S. Army Engineer Waterways Experiment Station, Narragansett, RI.

Environmental Systems Research Institute, Inc. (1992). "Introduction to Arcview GIS,” Redlands, CA.

Gailani, J. Z. (1998). “LTFATE cohesive sediment transport model,” DOER Technical Notes Collection (Technical Note DOER-N1), U.S. Army Engineer Waterways Experiment Station, Vicksburg, MS.

www.wes.army.mil/el/dots/doer

Luettich, R. A., Westerink, J. J., and Scheffner, N. W. (1992). “ADCIRC: An advanced three-dimensional circulation model for shelves, coasts, and estuaries,” Technical Report DRP-92-6, U.S. Army Engineer Waterways Experiment Station, Vicksburg, MS.

Scheffner, N. W., Thevenot, M. M., Tallent, J. R., and Mason, J. M. (1995). "LTFATE: A model to investigate the long-term stability of dredged material disposal sites," Technical Report DRP-95-1, U.S. Army Engineer Waterways Experiment Station, Vicksburg, MS.

NOTE: The contents of this technical note are not to be used for advertising, publication, or promotional purposes. Citation of trade names does not constitute an official endorsement or approval of the use of such products. 